Raper, M., Brough, P., \& Biggs, A. Evidence for the impact of organizational resources verses job characteristics in assessments of occupational stress over time. Applied Psychology: An International Review. Accepted 25/4/19.

Evidence for the impact of organisational resources versus job characteristics in assessments of occupational stress over time

Mitchell Raper,* Paula Brough, and Amanda Biggs

School of Applied Psychology, Griffith University, Australia

*Correspondence concerning this article should be addressed to: Mitchell Raper, School of Applied Psychology, Griffith University, Mount Gravatt Campus, Queensland 4122, Australia. Email: mitchell.raper@griffithuni.edu.au; Telephone +6137353302

Acknowledgements: The authors acknowledge the assistance provided by the Queensland Police Service. The views expressed in this material are those of the authors and are not those of the Queensland Police Service. Responsibility for any errors of omission or commission remains with the authors. The Queensland Police Service expressly disclaims any liability for any damage resulting from the use of the material contained in this publication and will not be responsible for any loss, howsoever arising, from use of or reliance on this material. This research was funded by a Queensland Smart State Senior Researcher Fellowship Grant, and this support is gratefully acknowledged. The assistance of Jennifer Barbour with part of the data collection is acknowledged.

Funding: This research is funded by a Queensland Smart State Senior Researcher Fellowship and this support is gratefully acknowledged. 


\begin{abstract}
Considerable evidence demonstrates the importance of both job demands and job resources in the prediction of employee health and motivational outcomes. However, scant empirical evidence explains how broader organisational factors can also have an impact on these outcomes. Utilising the job demands-resources (JD-R) model as a theoretical explanation of occupational stress, we examined the impact of employees' alignment with their organisation's strategic objectives (strategic alignment) in predicting long-term occupational health outcomes. The sample consisted of 1,601 police officers employed in one Australian police service, who completed two self-report surveys over 12-months. Results of the study indicated that strategic alignment was the only resource to reduce psychological strain, and to increase work engagement over time. Job demands were not found to be significantly associated with either psychological strain or work engagement over time. There was also no evidence of the moderating effects of job resources on health and motivational outcomes. The theoretical and practical implications of the inclusion of strategic alignment as an organisational resource are discussed.
\end{abstract}

Keywords: Strategic alignment, job demands-resources, work engagement, psychological strain. 


\section{Evidence for the impact of organisational resources versus job characteristics in assessments of occupational stress over time}

Minimising stress-related mental health injuries and enhancing positive work experiences, such as an employee's levels of work engagement, are a primary concern for organisations. Occupational stress can clearly produce substantial economic costs and adverse effects on employees' health and job performance outcomes (Brough, O'Driscoll, Kalliath, Cooper, \& Poelmans, 2009; Ganster \& Perrewe, 2011). The commonly accepted causes of occupational stress are unambiguous: namely excessive job demands, inadequate work resources, and exposure to psychologically unhealthy work environments (Brough, Drummond, \& Biggs, 2018). What remains pertinent is that despite these known antecedents, both the experiences and costs of occupational stress continue to increase, ensuring that occupational stress remains acknowledged as a significant global health problem (Hassard, Teoh, Visockaite, Dewe, \& Cox, 2018). One important avenue of occupational stress research is, therefore, to refine our knowledge and understanding of the known occupational stress antecedents.

In reference to current discussions concerning the inclusion of both individualfocused and broader organisational-focused job characteristics (e.g., Albrecht, Breidahl, \& Marty, 2018), this research assesses the role of job characteristics commonly included in theoretical explanations of occupational stress (i.e., job demands, job control, and social support), as well as the broader organisational-focused job resource of strategic alignment. Evidence suggests that high levels of this strategic alignment resource are effective in facilitating employee health and well-being (Biggs, Brough, \& Barbour, 2014b), albeit modified by calls for replication. Strategic alignment refers to an employee's line of sight between job tasks and the organisation's strategic priorities and is formally defined as including three considerations: “an employee's awareness of their organisation's strategic priorities; perceived importance of those priorities; and an understanding of how their daily 


\section{STRATEGIC ALIGNMENT AND JOB RESOURCES}

job tasks and roles directly contribute to the organisation's capacity to achieve its priorities" (Biggs et al., 2014b, p. 301). Employees' perception of strategic alignment is an important antecedent for the inclination of employees to invest their personal energy into the performance of job tasks and can, therefore, offset the detrimental effects of their job demands. Evidence indicates a clear line of sight with an organisation's strategic priorities can create a sense of meaning and importance of an employee's job demands, thus generating a better understanding of how job demands align with the organisation's objectives (Biggs et al., 2014b; Boswell, 2006). This increased job clarity is also associated with a supportive and autonomous work environment (Boswell, 2006).

In a longitudinal test of the relationships between strategic alignment, job control, social support, and work engagement, Biggs et al. (2014a) found that significant reciprocal associations occurred between these variables over time. These authors inferred that these reciprocal relationships are indicative of reduced perceptions of job demands, predominantly due to an increased sense of meaning, purpose, and other key psychological needs. For example, employees with high perceptions of strategic alignment may perceive their job demands as less threatening due to their increased psychological needs, as compared to employees who are less aligned with their organisation's strategic priorities (Biggs et al., 2014a). Biggs and colleagues (2014b) described the role of strategic alignment as a pertinent organisational job resource, similar to other more commonly examined job resources such as job support and job control. Thus strategic alignment can have both direct effects and indirect effects (via moderation) upon the negative outcomes associated with occupational stress, while enhancing positive outcomes such as work engagement. The current research advances these discussions, by comparing the long-term impacts of job support, job control, and strategic alignment in the assessment of psychological strain and work engagement in a sample of high-risk of stress workers (police officers). 
STRATEGIC ALIGNMENT AND JOB RESOURCES

\section{Assessing Employee's Mental Health}

The effective promotion of employee mental health focuses not only on reducing occupational stress experiences, but also on increasing positive outcomes, such as work engagement. This requires a comprehensive understanding of factors that facilitate positive outcomes, whilst minimising negative outcomes associated with specific occupational roles. Evidence suggests that positives outcomes such as work engagement, are associated in turn with increased job performance and organisational commitment (Hakanen \& Roodt, 2010), and decreased employee turnover (Schaufeli \& Bakker, 2004). Theoretical explanations, including the job demands-control support model (Johnson \& Hall, 1988) and the job demands-resources model (JD-R; Demerouti, Bakker, Nachreiner, \& Schaufeli, 2001), described how common (generic) job characteristics influence both positive and negative employee outcomes. The current research employs the JD-R model as a theoretical framework to assess two common outcomes of employee mental health: psychological strain and work engagement.

Psychological strain is commonly included in assessments of occupational stress as a context-free outcome, similar to psychological burnout, and is characterised by assessing mental health problems focused on anxiety, depression, and social withdrawal (Jackson, 2006; Kalliath, O'Driscoll, \& Brough, 2004; Shevlin \& Adamson, 2005). Psychological strain is widely adopted to identify individual experiences of distress and can also be utilised as a proxy of job performance problems including most commonly work absenteeism, low productivity, and turnover intentions (Boyd et al., 2011; Jackson, 2006; Mansell, Brough, \& Cole, 2006).

Work engagement is defined as a positive, work attitude characterised by three components: vigour, dedication, and absorption (Schaufeli, Salanova, González-Romá, \& Bakker, 2002). Vigour refers to highly resilient, energetic employees who invest effort in 


\section{STRATEGIC ALIGNMENT AND JOB RESOURCES}

their work while having the ability to persist with difficult tasks; dedicated employees combine a sense of enthusiasm, inspiration, and pride; and absorption refers to deep concentration in, and difficulty in detaching from, one's work with time passing quickly.

The assessment of psychological strain and work engagement in the current research provides a comprehensive overview of employee well-being from a health (psychological strain) perspective, while also identifying levels of a workplace attitude (work engagement) commonly included in applications of the JD-R model.

\section{The Job Demands-Resources Model}

The JD-R model offers an explanation of occupational stress based on two categories of work experiences: job demands and job resources, which each directly impact employee well-being and motivation (Demerouti et al., 2001). The strain process describes how excessive job demands cause employees to become overwhelmed by their work, leading to exhaustion, burnout, and a range of health and psychological problems through the continual depletion of their energy. The motivational process describes how exposure to job resources increase motivation in employees leading to high levels of work engagement. Importantly, the JD-R model also suggests the interactions of job demands and job resources impacts both the strain process and the motivational process ( Bakker, Demerouti, \& Euwema, 2005). This buffering hypothesis posits that differing levels of job demands and job resources can alleviate (moderate) health outcomes, with the strongest effects occurring when job resources are perceived to be high, thus facilitating effective coping strategies when faced with heightened job demands ( Bakker, Demerouti, \& Sanz-Vergel, 2014; Brough et al., 2013).Job demands are defined as aspects of a job that require physical, mental, or emotional effort and are directly associated with burnout and psychological strain (Bakker \& Demerouti, 2007). Common job demands include high work pressure, unfavourable physical environments, and high levels of emotional demands (Bakker \& Demerouti, 2007; Brough et al., 2018). Chronic 


\section{STRATEGIC ALIGNMENT AND JOB RESOURCES}

exposure to job demands, coupled with a perceived inability to accomplish these demands, produces occupational stress experiences (Biggs, Brough, \& Drummond, 2017).

Job resources are aspects of a job that enable employees to achieve work goals, mitigate job demands, and stimulate personal growth, learning, and development (Demerouti et al., 2001). Common job resources include social support and job control (Bakker \& Demerouti, 2007; Brough et al., 2018), primarily due to the influence of the job demandscontrol-support model (Johnson \& Hall, 1988). Colleague support alleviates employee stress through positive occupational networks and organisational citizenship behaviours (Luchman \& Gonzalez-Morales, 2013), providing opportunities for employees both practically (e.g., assistance to complete a task on time) and emotionally (e.g., discussions to reduce the negative impact of job demands; Brough \& Pears, 2004). Supervisor support may also alleviate distress by providing helpful information and work appreciation, facilitating coping and job performance (Brough \& Pears, 2004; Van der Doef \& Maes, 1999). Job control assists employees in gaining independence and decision-making in completing work tasks, allowing employees to rearrange methods to complete tasks, enabling workers more opportunities to cope with stressors such as overload and timing pressures ( Brough et al., 2018; Demerouti \& Bakker, 2011; Luchman \& Gonzalez-Morales, 2013; Van der Doef \& Maes, 1999).

Evidence generally supports the strain and motivational processes proposed by the JD-R model, but the buffering hypothesis has received mixed support. For example, Schaufeli, Bakker, and Van Rhenen (2009) reported support for both the strain and motivational processes over a one year period. Both Hakanen, Perhoniemi, and ToppinenTanner (2008) and Hakanen, Schaufeli, and Ahola (2008) also reported positive and reciprocal cross-lagged relations between job resources, work engagement, organisational commitment, burnout, and personal initiative over a two-wave, three-year time lag. Similarly, 


\section{STRATEGIC ALIGNMENT AND JOB RESOURCES}

both Hall, Dollard, Tuckey, Winefield, and Thompson (2010) and Martinussen, Richardsen, and Burke (2007) also reported support for both JD-R processes over time in samples of Australian and Norwegian police officers, respectively. Recent research investigating episodic changes (i.e., processes occurring within the moment) in work engagement reported that resources were positively associated with both work engagement and job performance (Reina-Tamayo, Bakker, \& Derks, 2017). Finally, a number of reviews and meta-analyses have also demonstrated the hypothesised effects of the strain and motivational processes proposed by the JD-R model (e.g., Halbesleben, 2010; Luchman \& Gonzalez-Morales, 2013; Nahrgang, Morgeson, \& Hofmann, 2011). Interestingly however, some research has failed to replicate these findings and has produced limited support for either the dual processes and/or the job demands $\mathrm{x}$ job support/control interaction terms described by the JD-R model (e.g., Boyd et al., 2011; Brough \& Biggs, 2015; Brough et al., 2013; Deacon \& Brough, 2016; Schneider, Hornung, Weigl, Glaser, \& Angerer, 2017; Taris, 2006). These discrepancies in findings warrants further assessments of the interaction hypotheses within the occupational stress process.

Importantly, the vast majority of research testing the JD-R model to date has focused on job-level resources. However, pertinent job resources may also arise from the broader organisational context; a proposition which has been largely neglected by empirical work to date (Albrecht, 2012; Albrecht et al., 2018). Expanding the JD-R model to include organisational-level resources may for example, provide a more parsimonious explanation of the antecedents of occupational stress (e.g., Bakker \& Demerouti, 2018).

\section{The Current Research}

The aim of the current research is to compare assessments of two commonly assessed job resources (job control and job support) and a 'broader' organisational resource (strategic alignment) within the application of the JD-R model, for the long-term prediction of two 


\section{STRATEGIC ALIGNMENT AND JOB RESOURCES}

common outcomes: psychological strain and work engagement. Mitigating occupational stress and enhancing positive outcomes is challenging in all occupational contexts, but is especially difficult in the high-risk of stress occupations, such as policing, which is the research sample included in this study. Police officers are not only exposed to organisational constraints common to all occupations, but also experience routine and traumatic operational stressors, emotionally demanding interpersonal interactions, intense scrutiny over their actions, unprecedented change, and increasingly austere work conditions ( Brough, Brown, \& Biggs, 2016a). Occupational stress experienced by police officers has been widely associated with numerous physiological and psychological outcomes including: alcohol and drug misuse, fatigue, and post-traumatic stress (Brough, 2005; Brough, Chataway, \& Biggs, 2016b; Brown \& Campbell, 1990; Richardsen, Burke, \& Martinussen, 2006). Police officers typically also report below average levels of physical health, psychological well-being, and job satisfaction (Johnson et al., 2005); experience high levels of both organisational and operational work hassles (Hart, Wearing, \& Headey, 1995); are more likely to worry about job difficulties after work; and find it more difficult to unwind after work, in comparisons with employees from other occupational groups (Brough \& Biggs, 2010; Brough, Brown et al., 2016).

The current research aims to add causal validity to the JD-R model via assessments of the model's propositions over a one-year period. Validation of the JD-R model within research adopting prospective and longitudinal designs has been recommended (e.g., Brough et al., 2013). The current research also aims to replicate and extend the work of Biggs and colleuages (2014b) by assessing strategic alignment as a pertinent organisational resource via both the motivational and strain processes of the JD-R model. This research aims to understand how this organisational resource may offset the detrimental effects of job 
demands as described by the buffering hypothesis. The current research therefore tests three research hypotheses:

Hypothesis 1: Job demands will be positively associated over time with psychological strain (1a) and negatively associated with work engagement (1b).

Hypothesis 2: The job resources of supervisor support, colleague support, and job control, and the organisational resource of strategic alignment, will each be negatively associated over time with psychological strain (2a) and positively associated with work engagement $(2 b)$.

Hypothesis 3: The job resources of supervisor support, colleague support, and job control, and the organisational resource of strategic alignment, will each moderate over time the relationship between job demands and psychological strain and work engagement. Increased resources (at Time 1) will reduce the associations between job demands and psychological strain (at Time 2; H3a); and will increase the associations with work engagement (at Time 2; H3b).

\section{Method}

\section{Participants and Procedure}

An online self-report questionnaire was electronically administered (via the organisation's internal email system) to all employees of one Australian State Police Service (approximately 15,000 employees) twice over a 12-month period. The survey was confidential and the invitation to participate in the research came from the university researchers, who managed the data collection process. All data were returned to the university researchers for analysis. A total of 5,021 completed surveys were returned at Time 1 (38\% response rate) and 4,477 completed surveys were returned at Time 2 (34\% response rate). Sworn police officers who could be matched as completing both surveys (via a selfreport code word) are the focus of this paper $(N=1,601)$. The majority of these respondents 


\section{STRATEGIC ALIGNMENT AND JOB RESOURCES}

were male $(n=1,250 ; 79 \%)$ and were employed full-time $(n=1,519 ; 96 \%)$. Half of the sample were either constables or senior constables $(n=817 ; 51 \%)$, followed by sergeants and senior sergeants $(n=668 ; 41 \%)$, then inspectors and superintendents $(n=120 ; 8 \%)$. The respondents average age was 41 years, ranging from 21 years to 58 years $(S D=7.84$ years). Respondents worked on average 43.5 hours per week ( $S D=8$ hours) and had an average organisational tenure of 16 years $(S D=10$ years $)$.

A multivariate analysis of variance (MANOVA) was conducted to examine differences between non-completers (Time 1 only) and completers (Time 1 and 2) on the research variables and these results are summarised in Table 1. Employing Wilks' Lambda, a statistically significant difference was produced between completers and non-completers on the combined dependent variables, $F(7,3345)=7.94, p<.001 ; \Lambda=.98 ; \eta_{\mathrm{p}}{ }^{2}=.02$, observed power $=1$.Univariate analyses of job control and strategic alignment were significantly higher in completers than non-completers, while colleague support was significantly lower in the completer sample.

\section{INSERT TABLE 1 ABOUT HERE}

\section{Measures}

Job demands and job control. Wall, Jackson, and Mullarkey's (1995) job characteristics measure was included to assess cognitive job demands and job control. Job demands was measured with the problem-solving job demands subscale (five items; e.g., "Do you come across problems in your job you have not met before?") Job control was assessed with the four item subscale assessing timing control, example items include "Do you decide on the order in which you do things?" Answers were recorded on a five-point scale ranging from 1 (Not at all) to 5 (A great deal). High scores indicate high levels of job demands and job control respectively. 
Supervisor support and colleague support. Supervisor support and colleague support were measured with two social support subscales (Caplan, Cobb, French, Van Harrison, \& Pinneau, 1980). Participants were asked to rate perceived support from their supervisor (four items) and colleagues (four items). An example item is "How much does each of these people do things to make your work life easier for you: (a) Your immediate supervisor and (b) other people at work (colleagues)?" Answers were recorded on a fivepoint scale ranging from 0 (Don't have such a person) to 4 (Very much). High scores indicate high levels of support.

Strategic alignment. Strategic alignment was measured with a four-item scale (Biggs et al., 2014b). An example item is "I have a clear understanding of how my workgroup's operational priorities help the Service achieve its strategic objectives". Responses were made on a seven-point scale ranging from 1 (Strongly disagree) to 7 (Strongly agree), with high scores representing a high degree of alignment with the strategic priorities authorised by the organisation.

Psychological strain. The 12-item General Health Questionnaire (GHQ; Goldberg, 1972) was included to assess psychological strain. Respondents were asked to report the extent to which they currently experienced 12 different symptoms of psychological strain. Responses were recorded on a four-point response scale. Example items include "Lost much sleep over worry?" ( 0 = Not at all, 3 Much more than usual) and "Been able to enjoy your day-to-day activities?" ( 0 = More so than usual", 3 = Much less than usual). High scores indicate high strain. Previous research has indicated a three factor model of the GHQ consisting of anxiety/depression, social dysfunction, and loss of confidence (Boyd et al., 2011; Shevlin \& Adamson, 2005). Confirmatory factor analyses also supported this three factor model in the current data $\left(\chi^{2}(41)=333.98, \chi^{2} / d f=8.15, p<.001 ;\right.$ CFI $=.96$; TLI $=95$; RMSEA $=.07 ;$ SRMR $=.03)$. 
Work engagement. The nine-item Utrecht Work Engagement Scale (UWES; Schaufeli, Bakker, \& Salanova, 2006) was included to measure work engagement. An example items is: "At my work, I feel bursting with energy". Responses were made on a seven-point scale ranging from 0 (Never) to 6 (Everyday). High scores represent high levels of work engagement. Previous research indicates a three factor model of engagement consisting of vigour, dedication, and absorption (Schaufeli et al., 2006). Confirmatory factor analyses revealed this three factor model was also supported by the current data $\left(\chi^{2}(24)=\right.$ 286.77, $\left.\chi^{2} / d f=11.95, p<.001 ; \mathrm{CFI}=.98 ; \mathrm{TLI}=97 ; \mathrm{RMSEA}=.08 ; \mathrm{SRMR}=.04\right)$. Each research measure demonstrated an acceptable level of reliability and these are depicted on the diagonal of Table 2 .

\section{Statistical Analysis}

The statistical analyses were conducted with SPSS (IBM SPSS Statistics software, version 25; IBM Corp) and AMOS (Version 25; Arbuckle, 2017). For each structural model, individual items were employed as indicators for the latent variables of job demands, job control, supervisor support, colleague support, and strategic alignment (Bagozzi \& Heatherton, 1994). Subscale scores were utilised as indicators for the latent variables of work engagement and psychological strain to reduce the chance of random error occurring due to the higher number of indicators in each of the UWES and GHQ. This method is appropriate as this paper is focusing on the relationship between these latent constructs over time rather than the underlying factor structures of each latent variable (Bagozzi \& Edwards, 1998). For each model tested, Time 1 latent variables were allowed to correlate and each Time 1 indicator error term was allowed to covary with its respective Time 2 counterpart.

To test Hypotheses 1 and 2, five cross-lagged structural models were compared to assess the relationships between job demands, job resources, and the outcome variables over time. First, a unidirectional model was constructed which included all Time 1 variables and 


\section{STRATEGIC ALIGNMENT AND JOB RESOURCES}

their Time 2 counterparts. Second, a dual pathway model was tested to determine whether job demands predicted psychological strain and job resources predicted work engagement over time. Third, a cross-linked model was assessed to ascertain whether job demands predicted work engagement and job resources predicted psychological strain over time. Next, a reciprocal model assessed how well psychological strain and work engagement at Time 1 predicted job demands and job resources at Time 2. The final model included all pathways from all Time 1 variables onto all Time 2 variables.

In order to test for the moderating effects of job demands and job resources on the outcome variables (Hypothesis 3), three indicators were constructed for each latent interaction term (Marsh, Wen, \& Hau, 2004). The observed product term indicators were computed in two steps. First, the three highest loading items of job demands, job autonomy, supervisor and colleague support, and strategic alignment were each standardized. Second, job demands $\mathrm{x}$ job resource interaction terms were produced by multiplying the highest item loadings within each of these two scales, then the second highest loadings, and then the third highest loadings (Marsh et al., 2004). Each interaction term was tested individually, resulting in a total of four different SEM models. A significant interaction term is deemed to produce both an acceptable model fit and significant regression paths between the interaction and the outcome variables. Additional support is obtained if the model fit is improved with the included interaction pathway, compared to being constrained to zero (Marsh et al., 2004).

\section{Results}

\section{Scale Descriptives}

The scale descriptives and bivariate correlations for the Time 1 and Time 2 research variables are summarised in Table 2. It can be seen that job demands displayed weak positive relationships with both psychological strain and work engagement. The four job and organisational resources showed negative associations with psychological strain, and positive 
associations with work engagement. As expected, work engagement displayed moderate negative correlations with psychological strain at both times.

\section{INSERT TABLE 2 ABOUT HERE}

\section{Tests of Longitudinal Structural Equation Models}

The results of the series of structural models constructed to test Hypotheses 1 and 2 are summarised in Table 3. Acceptable model fit statistics were obtained for each of the five structural models. Chi-square difference testing revealed significant differences between all of the models with the largest differences occurring between Models 3 and 4, and Models 1 and 5.

Figure 1 illustrates the significant pathways between job demands, job resources, work engagement, and psychological strain (Model 5 from Table 3). All Time 1 variables significantly predicted their Time 2 counterparts. However, job demands did not significantly predict either psychological strain nor work engagement over time, offering no support to Hypothesis 1. Similarly, job control, supervisor support, and colleague support were also each not associated with either psychological strain or work engagement. Strategic alignment was found to significant predict both psychological strain and work engagement in the hypothesised direction, offering partial support to Hypothesis 2.

\section{INSERT TABLE 3 AND FIGURE 1 ABOUT HERE}

Table 4 summarises the results of the moderated structural equation modelling. Despite all four models showing adequate fit, no significant interactions occurred between job demands and the job/organisational resources for the prediction of either work engagement or psychological strain over time. Furthermore, the addition of these interaction terms did not increase the amount of variance explained in either of the outcome variables. Finally, comparing the models when the interaction pathways were constrained to zero did not significantly change the chi-square statistic, thus offering no support to Hypothesis 3. 


\section{INSERT TABLE 4 ABOUT HERE}

\section{Discussion}

The current study investigated occupational stress over time experienced by a sample of police officers and specifically assessed strategic alignment as an organisational resource in the estimation of both work engagement and psychological strain. Interestingly, we found that job demands produced no significant relationships for the assessments of psychological strain and work engagement over time (Hypotheses $1 \mathrm{a}$ and $1 \mathrm{~b}$ respectively). Job resources had some impact in predicting the two outcomes over time, with strategic alignment explaining more variance, as compared to both job control and job support; offering partial support for Hypotheses $2 \mathrm{a}$ and $2 \mathrm{~b}$. Interestingly, we found no support for the buffering hypothesis (Hypothesis 3) described by the JD-R model, as no significant interactions terms from the total of four tested were produced by this research.

\section{Theoretical Implications of the Research Findings}

Impact of job demands. The strain process of the JD-R model was not supported by this research, which was unexpected. Job demands were not a significant predictor of either psychological strain or work engagement over time. Other longitudinal research has also reported similar non-significant findings of this strain process (Boyd et al., 2011; Brough et al., 2013; Schneider et al., 2017) but an accurate explanation for why job demands was found to be a non-significant predictor is difficult to ascertain. One explanation focuses on the measurement of job demands. Previous research has for example, identified the importance of assessing occupational-specific job demands as well as generic job demands for the more accurate estimation of occupational stress and wellbeing. These occupational-specific job demands have been identified as key antecedents of occupation stress for a variety of highrisk of stress employees, including police officers (Brough \& Biggs, 2015; Hart, Wearing \& Headey, 1995), correctional officers (e.g., Brough \& Biggs, 2015; Brough \& Williams, 


\section{STRATEGIC ALIGNMENT AND JOB RESOURCES}

2007), and teachers (e.g., Collie, Shapka, Perry, \& Martin, 2015). It does seem pertinent to assess specific job characteristics identified as being particularly unpleasant for the targeted research sample (for police officer job demands this include items such as "attending a road accident" and "delivering a death message"; Brough \& Biggs, 2015). The non-significant associations between job demands and both outcomes produced by this research, could therefore be influenced by the appropriate measure of job demands. Future research is therefore, recommended to consider in detail the pertinence of the job characteristics being assessed, especially when estimating stress and wellbeing experienced by high-risk occupational groups.

A second explanation for the lack of significant associations produced by job demands in this research, is based on other categorisation of demands. Recent work suggests that distinguishing between positive (challenges) and negative (hindrances) job demands is also a valuable categorisation for the more accurate estimation of occupational stress and wellbeing (e.g., Tuckey, Searle, Boyd, Winefield, \& Winefield, 2015; Van den Broeck, De Cuyper, De Witte, \& Vansteenkiste, 2010). Similarly, for samples of public service workers in frequent contact with the public (including police officers), the value of assessing emotional job demands has also been reported (e.g., Brough et al., 2018; Loh, Idris, Dollard, $\&$ Isahak, 2018). The current research unfortunately, only included one assessment of generic cognitive job demands but clearly, the inclusion of multiple types of job demands is a recommended consideration for future research.

Impact of strategic alignment. Strategic alignment was significantly associated with psychological strain and work engagement over time in the current research, partially supporting Hypotheses $2 \mathrm{a}$ and $2 \mathrm{~b}$ respectively. This finding supports and extends initial work by Biggs and colleagues (2014b), and indicates that strategic alignment may be more important to the assessment of employee health and performance outcomes over time, as 


\section{STRATEGIC ALIGNMENT AND JOB RESOURCES}

compared to other job characteristics. Strategic alignment has been associated with other occupational and individual constructs, including: leadership, role clarity, personorganisation-fit, and goal congruence (Ateş, Tarakci, Porck, van Knippenberg, \& Groenen, 2018; Boswell, 2006; Boswell, Bingham, \& Colvin, 2006). It is possible that respondents with a high degree of strategic alignment are more involved in decision-making processes and receive increased recognition by managers due to their congruence with organisation fit, role clarity, and organisational goals, and are therefore, more engaged with their work, as compared to workers with low levels of strategic alignment (Albrecht et al., 2018). For example, Biggs and colleauges (2014b) highlighted the reciprocity between strategic alignment and work engagement, which could exemplify the resource gain spirals described by Hobfoll (2001). This explanation however, requires replication with a research design consisting of three or more time lags in order to explicitly demonstrate any consecutive resource gains (Lindsley, Brass, \& Thomas, 1995).

In their review of the JD-R model, Schaufeli and Taris (2014) queried the model's that assumptions that all job characteristics are equal, when it is plausible instead that not all job characteristics are equally valued by employees. From a conservation of resources (Hobfoll, 1989) perspective, the concept of resource allocation may directly influence the prioritisation of job resources. For instance, job control, supervisor support, and colleague support may not necessarily be as positively valued (appraised) when compared to organisational factors such as strategic alignment. This appears to have occurred in the current research when comparing the higher scores of strategic alignment in the completers sample versus the non-completers sample. However, we also acknowledge that the higher scores of strategic alignment in the completer sample may have created an inherent bias, as these respondents may have been more likely to complete the Time 2 survey. Future research 


\section{STRATEGIC ALIGNMENT AND JOB RESOURCES}

should attempt to assess this in a more representative sample to ascertain whether the effect of strategic alignment is consistent across both time and different samples.

Impact of job support and job control. Interestingly, this research offers no support for the impact of either supervisor support or job control as job resources predicting psychological strain or work engagement over time. Research assessing the job characteristics of police officers indicates that officers commonly report both low levels of job control and job support, and this is especially true of officers employed in the lower police ranks (Biggs \& Brough, 2017; Brough, Brown et al., 2016; Brough, Chataway et al., 2016). Certainly, the mean scores for job control reported by the current research were in the mid-range and were lower than the mean scores reported for job demands at both Time 1 and Time 2. It may be the case that for police officers and for other workers employed in highly controlled jobs (e.g., correction officers, security workers) experiencing high levels of individual job control is unrealistic, and so the common theoretical explanations of occupational stress may not be wholly relevant to these workers. Similar to the discussion recommending the assessment of different types of job demands above, the value of including job characteristics which these employees do have a degree of control over is pertinent and for example, may produce more instances of direct and/or indirect (moderating) effects with the outcome variables.

Buffering hypothesis. The buffering hypothesis suggests job resources are able to reduce the impact of job demands on stress outcomes (Bakker \& Demerouti, 2007). This research produced no significant job demands $\mathrm{x}$ job resources interaction terms, thereby offering no support for buffering hypothesis. Difficulty in obtaining significant job demands and job resources interactions has been previously acknowledged, particularly in prospective and longitudinal research designs (Brough et al., 2013, 2018; Schneider et al., 2017; Taris, 2006; Van der Doef \& Maes, 1999). The suggestions raised above, for the inclusion of 


\section{STRATEGIC ALIGNMENT AND JOB RESOURCES}

different and/or more specific types of job characteristics are obviously pertinent here. The assessment of more refined job characteristics is recommended to be a fruitful endeavour for future tests of the buffering hypothesis.

\section{Limitations and Future Research Directions}

While prospective research designs offer insight into causal relationships, a common misunderstanding is that causal inferences can be established (Taris \& Kompier, 2014). Schaufeli and Taris (2014) have noted the importance of examining reciprocal causation in assessments of the JD-R model, by research designs including more than two time points. Such research designs may better explain the potential gain cycles between high performance and desired work outcomes, including for example, the dynamic processes occurring between organisational/job resources and motivational outcomes. We therefore, acknowledge that the two time points included in the current research, offer a limited insight into the causal relationships reported here.

A second limitation of this study is the low effect sizes reported. Although moderate levels of variance were explained in the outcome variables, job demands, job resources, and the interactions terms each respectively, explained minimal proportions of variance within both psychological strain and work engagement, particularly after controlling for each variable at Time 1. It is of course, possible that perceived job demands and job resources at one point in time could have minimal impacts on outcomes one year later. Selecting appropriate time lags to acquire maximum effect sizes is a difficult issue in this field, with researchers selecting time lags that are either too short or too long to detect effects (Dormann \& Griffin, 2015). One possible explanation of the small effect sizes in this study may be due to the length of time employed to assess these stressor-strain reactions (Dormann \& van de Ven, 2014). The job characteristics included in this research could elicit mid-term stressreactions (i.e., between one day to one month), when a meso-term stress-reaction (i.e., 
approximately one year) was measured (Dormann \& van de Ven, 2014). We therefore, recommend future research include multiple waves of data collection, to enable researchers to better detect any change scores of participants between time points ( Dormann \& Guthier, 2018). Finally, we also acknowledge that the inclusion of strategic alignment as an organisational-level resource in subsequent research with other (non-police samples) is required, in order to assess the generalisability of the results produced here.

\section{Practical Implications}

The results of this study indicated strategic alignment increased levels of work engagement and reduced psychological strain over time. In other words, employees who are more aware of how their work aligns with the organisation's strategic objectives tend to be healthier over time. Strategic alignment could, therefore, be included as a human resource management tool to promote high levels of work engagement and wellbeing through training programs in establishing employees' line of sight with the organisation's strategic objectives. This could be achieved, for example, through educating employees on the organisation's strategic priorities and how they can each work towards, and have an impact upon, the organisations' goals (Biggs, Brough, \& Barbour, 2014a). Certainly, this suggestion has a recognised practical appeal: organisations are likely to consider it easier to produce 'strategic alignment training components' within an employee wellbeing program, as opposed to considering changes to reduce/improve more ambiguous employee job characteristics such as job demands or job control. However, further validation of the results reported by this research is required, before any such practical application can be fully recommended.

\section{Conclusions}

This research addressed calls to investigate organisational resources in predicting occupational health outcomes. Although the results of this research challenged previous findings of the JD-R model, some interesting points of discussion arose. The role of 
organisational resources in assessments of employee mental health should be recognised, particularly when considering the multi-level nature of the psychosocial work environment. Selecting optimal time lags in occupational health psychology research is of great importance to understand the complexity of stressor-strain relationships, and requires careful consideration. Future research is recommended to consider the type of stressor-strain relationship under investigation and select appropriate time lags to gain insight into the causal and temporal nature of these relationships. The application of the JD-R model in future assessments of occupational stress should also consider these recommendations, which may lead to more fruitful theoretical and practical implications. Finally, the importance of strategic alignment as an organisational resource is acknowledged and assists in preserving high quality service by police officers to the wider community. 


\section{References}

Albrecht, S. L. (2012). The influence of job, team and organizational level resources on employee well-being, engagement, commitment and extra-role performance. International Journal of Manpower, 33(7), 840-853. doi:10.1108/01437721211268357

Albrecht, S. L., Breidahl, E., \& Marty, A. (2018). Organizational resources, organizational engagement climate, and employee engagement. Career Development International, 23(1), 67-85. doi:10.1108/CDI-04-2017-0064

Arbuckle, J. L. (2017). Amos 25.0 User's Guide. Chicago: IBM SPSS.

Ateş, N. Y., Tarakci, M., Porck, J. P., van Knippenberg, D., \& Groenen, P. J. (2018). The dark side of visionary leadership in strategy implementation: Strategic alignment, strategic consensus, and commitment. Journal of Management, 0149206318811567.

Bagozzi, R. P., \& Edwards, J. R. (1998). A general approach for representing constructs in organizational research. Organizational Research Methods, 1, 45-87. doi:10.1177/109442819800100104

Bagozzi, R. P., \& Heatherton, T. F. (1994). A general approach to representing multifaceted personality constructs: Application to state self-esteem. Structural Equation Modeling, 1(1), 35-67. doi:10.1080/10705519409539961

Bakker, A. B., \& Demerouti, E. (2007). The Job Demands-Resources model: State of the art. Journal of Managerial Psychology, 22(3), 309-328. doi:10.1108/02683940710733115

Bakker, A. B., \& Demerouti, E. (2018). Multiple levels in job demands-resources theory: Implications for employee well-being and performance. In E. Diener, S. Oishi, \& L. Tay (Eds.), Handbook of well-being. Salt Lake City, UT: DEF Publishers. 


\section{STRATEGIC ALIGNMENT AND JOB RESOURCES}

Bakker, A. B., Demerouti, E., \& Euwema, M. C. (2005). Job resources buffer the impact of job demands on burnout. Journal Occupational Health Psychology, 10(2), 170-180. doi:10.1037/1076-8998.10.2.170

Bakker, A. B., Demerouti, E., \& Sanz-Vergel, A. I. (2014). Burnout and work engagement: The JD-R approach. Annual Review of Organizational Psychology and Organizational Behavior, 1(1), 389-411. doi:10.1146/annurev-orgpsych-031413091235

Biggs, A., \& Brough, P. (2017). Effects of police culture and support on work and non-work outcomes. In R. J. Burke (Ed.), Stress in policing: Sources, consequences, and interventions. (pp. 309-322). London, UK: Taylor \& Francis Ltd.

Biggs, A., Brough, P., \& Barbour, J. P. (2014a). Relationships of individual and organizational support with engagement: Examining various types of causality in a three-wave study. Work and Stress, 28(3), 236-254.

doi:10.1080/02678373.2014.934316

Biggs, A., Brough, P., \& Barbour, J. P. (2014b). Strategic alignment with organizational priorities and work engagement: A multi-wave analysis. Journal of Organizational Behavior, 35(3), 301-317. doi:10.1002/job.1866

Biggs, A., Brough, P., \& Drummond, S. (2017). Lazarus and Folkman's psychological stress and coping theory. In C. Cooper \& J. C. Quick (Eds.), The Wiley handbook of stress and health: A guide to research and practice. London, UK: John Wiley and Sons.

Boswell, W. (2006). Aligning employees with the organization's strategic objectives: out of 'line of sight', out of mind. International Journal of Human Resource Management, 17(9), 1489-1511. doi:10.1080/09585190600878071

Boswell, W., R., Bingham, J. B., \& Colvin, A. J. S. (2006). Aligning employees through 'line of sight'. Business Horizons, 49(6), 499-509. doi:10.1016/j.bushor.2006.05.001 
Boyd, C. M., Bakker, A. B., Pignata, S., Winefield, A. H., Gillespie, N., \& Stough, C. (2011). A Longitudinal Test of the Job Demands-Resources Model among Australian University Academics. Applied Psychology:-An International Review, 60(1), 112-140. doi:10.1111/j.1464-0597.2010.00429.x

Brough, P. (2005). A comparative investigation of the predictors of work-related psychological well-being within police, fire and ambulance workers. New Zealand Journal of Psychology, 34(2), 127-134.

Brough, P., \& Biggs, A. (2010). Occupational stress in police and prison staff. In J. Brown \& E. Campbell (Eds.), The Cambridge handbook of forensic psychology (pp. 707-718). Cambridge, UK: Cambridge University Press.

Brough, P., \& Biggs, A. (2015). Job demands x job control interaction effects: do occupationspecific job demands increase their occurrence? Stress \& Health, 31(2), 138-149. doi:10.1002/smi.2537

Brough, P., Brown, J., \& Biggs, A. (2016). Improving criminal justice workplaces: Translating theory and research into evidenced-based practice. London: Routledge.

Brough, P., Chataway, S., \& Biggs, A. (2016). 'You don't want people knowing you're a copper!' A contemporary assessment of police organisational culture. International Journal of Police Science \& Management, 18(1), 28-36. doi:10.1177/1461355716638361

Brough, P., Drummond, S., \& Biggs, A. (2018). Job support, coping, and control: Assessment of simultaneous impacts within the occupational stress process. Journal Occupational Health Psychology, 23(2), 188-197. doi:10.1037/ocp0000074

Brough, P., O'Driscoll, M., Kalliath, T., Cooper, C., \& Poelmans, S. A. Y. (2009). Workplace psychological health: current reserach and practice. Cheltenham, UK: Edward Elgar. 


\section{STRATEGIC ALIGNMENT AND JOB RESOURCES}

Brough, P., \& Pears, J. (2004). Evaluating the influence of the type of social support on job satisfaction and work related psychological well-being. International Journal of Organisational Behaviour, 8(2), 472-485.

Brough, P., Timms, C., Siu, O. L., Kalliath, T., O'Driscoll, M. P., Sit, C. H. P., . . Lu, C. Q. (2013). Validation of the Job Demands-Resources model in cross-national samples: Cross-sectional and longitudinal predictions of psychological strain and work engagement. Human Relations, 66(10), 1311-1335. doi:10.1177/0018726712472915

Brough, P., \& Williams, J. (2007). Managing occupational stress in a high-risk industry Measuring the job demands of correctional officers. Criminal Justice and Behavior, 34(4), 553-+. doi:10.1177/0093854806294147

Brown, J. M., \& Campbell, E. A. (1990). Sources of Occupational Stress in the Police. Work and Stress, 4(4), 305-318. doi:Doi 10.1080/02678379008256993

Caplan, R. D., Cobb, B., French, J. R. P., Jr., Van Harrison, R., \& Pinneau, S. R. (1980). Job demands and work health: Main effects and occupational differences. Ann Arbor, MI: Survey Research Center, Institute for Social Research, University of Michigan.

Collie, R. J., Shapka, J. D., Perry, N. E., \& Martin, A .J. (2015). Teacher well-being: Exploring its components and a practice-oriented scale. Journal of Psychoeducational Assessment, 33(8), 744-756. doi: 10.1177/0734282915587990

Deacon, R. E., \& Brough, P. (2016). Veterinary nurses' psychological well-being: The impact of patient suffering and death. Australian Journal of Psychology, 69(2), 77-85. doi:10.1111/ajpy.12119

Demerouti, E., \& Bakker, A. B. (2011). The Job Demands-Resources model: Challenges for future research. SA Journal of Industrial Psychology, 37(2), 1-9. doi:10.4102/sajip.v37i2.974 


\section{STRATEGIC ALIGNMENT AND JOB RESOURCES}

Demerouti, E., Bakker, A. B., Nachreiner, F., \& Schaufeli, W. B. (2001). The job demandsresources model of burnout. Journal of Applied Psychology, 86(3), 499-512. doi:10.1037//0021-9010.86.3.499

Dormann, C., \& Griffin, M. A. (2015). Optimal time lags in panel studies. Psychological Methods, 20(4), 489-505. doi:10.1037/met0000041

Dormann, C., \& Guthier, C. (2018). Longitudial data collection. In P. Brough (Ed.), Advanced research methods for applied psychology: Design, analysis, and reporting (pp. 146-157). London, UK: Routledge.

Dormann, C., \& van de Ven, B. (2014). Timing in methods for studying psychosocial factors at work. In M. F. Dollard, A. Shimazu, R. Bin Nordin, P. Brough, \& M. R. Tuckey (Eds.), Psychosocial Factors at Work in the Asia Pacific (pp. 89-116). London, UK: Springer.

Ganster, D. C., \& Perrewe, P. L. (2011). Theories of occupational stress. In J. C. Quick \& L. E. Tetrick (Eds.), Handbook of occupational health psychology (pp. 37-55). Washington, DC: American Psychological Association.

Goldberg, D. P. (1972). The detection of psychiatric illness by questionnaire. Oxford, UK: Oxford University Press.

Hakanen, J. J., Perhoniemi, R., \& Toppinen-Tanner, S. (2008). Positive gain spirals at work: From job resources to work engagement, personal initiative and work-unit innovativeness. Journal of Vocational Behaviour, 73(1), 78-91. doi:10.1016/j.jvb.2008.01.003

Hakanen, J. J., \& Roodt, G. (2010). Using the job demands-resources model to predict engagement: Analysing a conceptual model. In A. B. Bakker \& M. P. Leiter (Eds.), Work engagement: A handbook of essential theory and research (pp. 85-101). London, UK: Taylor \& Francis. 


\section{STRATEGIC ALIGNMENT AND JOB RESOURCES}

Hakanen, J. J., Schaufeli, W. B., \& Ahola, K. (2008). The Job Demands-Resources model: A three-year cross-lagged study of burnout, depression, commitment, and work engagement. Work and Stress, 22(3), 224-241. doi:10.1080/02678370802379432

Halbesleben, J. R. B. (2010). A meta-analysis of work engagement: Relationships with burnout, demands, resources and consequences. In A. B. Bakker \& M. P. Leiter (Eds.), Work engagement: A handbook of essential theory and research. New York, NY: Psychology Press.

Hall, G. B., Dollard, M. F., Tuckey, M. R., Winefield, A. H., \& Thompson, B. M. (2010). Job demands, work-family conflict, and emotional exhaustion in police officers: A longitudinal test of competing theories. Journal of Occupational and Organizational Psychology, 83(1), 237-250. doi:10.1348/096317908x401723

Hart, P. M., Wearing, A. J., \& Headey, B. (1995). Police Stress and Well-Being - Integrating Personality, Coping and Daily Work Experiences. Journal of Occupational and Organizational Psychology, 68(2), 133-156. doi:10.1111/j.2044-8325.1995.tb00578.x

Hassard, J., Teoh, K. R. H., Visockaite, G., Dewe, P., \& Cox, T. (2018). The cost of workrelated stress to society: A systematic review. Journal of Occupational Health Psychology, 23(1), 1-17. doi:10.1037/ocp0000069

Hobfoll, S. E. (1989). Conservation of Resources - a New Attempt at Conceptualizing Stress. American Psychologist, 44(3), 513-524. doi:Doi 10.1037//0003-066x.44.3.513

Hobfoll, S. E. (2001). The influence of culture, community, and the nested-self in the stress process: Advancing Conservation of Resources theory. Applied Psychology-an International Review-Psychologie Appliquee-Revue Internationale, 50(3), 337-370. doi:Doi 10.1111/1464-0597.00062 
STRATEGIC ALIGNMENT AND JOB RESOURCES

IBM SPSS Statistics for Windows, Version 25.0. Armonk, NY, USA: IBM Corp.Jackson, C. (2006). The General Health Questionnaire. Occupational Medicine, 57(1), 79-79. doi:10.1093/occmed/kq1169

Jackson, C. (2006). The General Health Questionnaire. Occupational Medicine, 57(1), 79-79. doi:10.1093/occmed/kq1169

Johnson, J. V., \& Hall, E. M. (1988). Job strain, work place social support, and cardiovascular disease: a cross-sectional study of a random sample of the Swedish working population. American Journal of Public Health, 78(10), 1336-1342. doi:10.2105/AJPH.78.10.1336

Johnson, S., Cooper, C., Cartwright, S., Donald, I., Taylor, P., \& Millet, C. (2005). The experience of work-related stress across occupations. Journal of Managerial Psychology, 20(2), 178-187. doi:10.1108/02683940510579803

Kalliath, T. J., O'Driscoll, M. P., \& Brough, P. (2004). A confirmatory factor analysis of the General Health Questionnaire-12. Stress and Health, 20(1), 11-20. doi:10.1002/smi.993

Lindsley, D. H., Brass, D. J., \& Thomas, J. B. (1995). Efficacy-Performance Spirals - a Multilevel Perspective. Academy of Management Review, 20(3), 645-678. doi:Doi $10.2307 / 258790$

Loh, M. Y., Idris, M. A., Dollard, M. F., \& Isahak, M. (2018). Psychosocial safety climate as a moderator of the moderators: Contextualizing JDR models and emotional demands effects. Journal of Occupational and Organizational Psychology, 91(3), 620-644. doi: 10.1111/joop.12211

Luchman, J. N., \& Gonzalez-Morales, M. G. (2013). Demands, control, and support: a metaanalytic review of work characteristics interrelationships. Journal of Occupational Health Psychology, 18(1), 37-52. doi:10.1037/a0030541 


\section{STRATEGIC ALIGNMENT AND JOB RESOURCES}

Mansell, A., Brough, P., \& Cole, K. (2006). Stable predictors of job satisfaction, psychological strain, and employee retention: An evaluation of organizational change within the New Zealand customs service. International Journal of Stress Management, 13(1), 84-107. doi:10.1037/1072-5245.13.1.84

Marsh, H. W., Wen, Z., \& Hau, K. T. (2004). Structural equation models of latent interactions: Evaluation of alternative estimation strategies and indicator construction. Psychological Methods, 9(3), 275-300. doi:10.1037/1082-989X.9.3.275

Martinussen, M., Richardsen, A. M., \& Burke, R. J. (2007). Job demands, job resources, and burnout among police officers. Journal of Criminal Justice, 35(3), 239-249. doi:10.1016/j.jcrimjus.2007.03.001

Nahrgang, J. D., Morgeson, F. P., \& Hofmann, D. A. (2011). Safety at work: a meta-analytic investigation of the link between job demands, job resources, burnout, engagement, and safety outcomes. Journal of Applied Psychology, 96(1), 71-94. doi:10.1037/a0021484

Reina-Tamayo, A. M., Bakker, A. B., \& Derks, D. (2017). Episodic Demands, Resources, and Engagement An Experience-Sampling Study. Journal of Personnel Psychology, 16(3), 125-136. doi:10.1027/1866-5888/a000177

Richardsen, A. M., Burke, R. J., \& Martinussen, M. (2006). Work and health outcomes among police officers: The mediating role of police cynicism and engagement. International Journal of Stress Management, 13(4), 555-574. doi:10.1037/10725245.13 .4 .555

Schaufeli, W. B., \& Bakker, A. B. (2004). Job demands, job resources, and their relationship with burnout and engagement: a multi-sample study. Journal of Organizational Behavior, 25(3), 293-315. doi:10.1002/job.248 


\section{STRATEGIC ALIGNMENT AND JOB RESOURCES}

Schaufeli, W. B., Bakker, A. B., \& Salanova, M. (2006). The measurement of work engagement with a short questionnaire - A cross-national study. Educational and Psychological Measurement, 66(4), 701-716. doi:10.1177/0013164405282471

Schaufeli, W. B., Bakker, A. B., \& Van Rhenen, W. (2009). How changes in job demands and resources predict burnout, work engagement, and sickness absenteeism. Journal of Organizational Behavior, 30(7), 893-917. doi:10.1002/job.595

Schaufeli, W. B., Salanova, M., González-Romá, V., \& Bakker, A. B. (2002). The measurement of engagement and burnout: A two sample confirmatory factor analytic approach. Journal of Happiness Studies, 3(1), 71-92. doi:10.1023/A:1015630930326

Schaufeli, W. B., \& Taris, T. W. (2014). A critical review of the job demands-resources model: Implications for improving work and health. In G. F. Bauer \& O. Hammig (Eds.), Bridging occupational, organizational and public health: A transdisciplinary approach (pp. 43-68). Netherlands: Springer.

Schneider, A., Hornung, S., Weigl, M., Glaser, J., \& Angerer, P. (2017). Does it matter in the long run? Longitudinal effects and interactions in the differentiated job demandsresources model. European Journal of Work and Organizational Psychology, 26(5), 741-754. doi:10.1080/1359432X.2017.1347561

Shevlin, M., \& Adamson, G. (2005). Alternative Factor Models and Factorial Invariance of the GHQ-12: A Large Sample Analysis Using Confirmatory Factor Analysis. Psychological Assessment, 17(2), 231-236. doi:10.1037/1040-3590.17.2.231

Taris, T. W. (2006). Bricks without clay: On urban myths in occupational health psychology. Work and Stress, 20(2), 99-104. doi:10.1080/02678370600863410

Taris, T. W., \& Kompier, M. A. J. (2014). Cause and effect: Optimizing the designs of longitudinal studies in occupational health psychology. Work and Stress, 28(1), 1-8. doi:10.1080/02678373.2014.878494 


\section{STRATEGIC ALIGNMENT AND JOB RESOURCES}

Tuckey, M. R., Searle, B. J., Boyd, C. M., Winefield, A. H., \& Winefield, H. R. (2015). Hindrances are not threats: advancing the multidimensionality of work stress. Journal of Occupational Health Psychology, 20(2), 131-147. doi:10.1037/a0038280

Van den Broeck, A., De Cuyper, N., De Witte, H., \& Vansteenkiste, M. (2010). Not all job demands are equal: Differentiating job hindrances and job challenges in the Job Demands-Resources model. European Journal of Work and Organizational Psychology, 19(6), 735-759. doi:10.1080/13594320903223839

Van der Doef, M., \& Maes, S. (1999). The Job Demand-Control (-Support) Model and psychological well-being: A review of 20 years of empirical research. Work and Stress, 13(2), 87-114. doi:10.1080/026783799296084

Wall, T. D., Jackson, P. R., \& Mullarkey, S. (1995). Further Evidence on Some New Measures of Job Control, Cognitive Demand and Production Responsibility. Journal of Organizational Behavior, 16(5), 431-455. doi:DOI 10.1002/job.4030160505 
STRATEGIC ALIGNMENT AND JOB RESOURCES

Table 1

Mean scores of research variables across Time 1 and 2 .

\begin{tabular}{|c|c|c|c|c|c|c|c|c|}
\hline \multirow{4}{*}{ Dependent Variables } & \multirow{3}{*}{\multicolumn{2}{|c|}{$\begin{array}{c}\text { Non- } \\
\text { Completers } \\
(N=1,752)\end{array}$}} & \multirow{2}{*}{\multicolumn{2}{|c|}{$\begin{array}{l}\text { Completers } \\
(N=1,601)\end{array}$}} & \multirow{4}{*}{$\begin{array}{c}\text { Type III sum } \\
\text { of squares }\end{array}$} & \multirow{4}{*}{$F$} & \multirow{4}{*}{$\eta_{\mathrm{p}}{ }^{2}$} & \multirow{4}{*}{$\begin{array}{c}\text { Observed } \\
\text { Power }\end{array}$} \\
\hline & & & & & & & & \\
\hline & & & \multirow[b]{2}{*}{$M$} & \multirow[b]{2}{*}{$S D$} & & & & \\
\hline & $M$ & $S D$ & & & & & & \\
\hline Job Demands & 3.76 & 0.80 & 3.78 & 0.78 & 0.32 & 0.51 & .00 & .11 \\
\hline Job Control & 3.43 & 0.99 & 3.59 & 0.98 & 21.43 & $22.05 * * *$ & .01 & .99 \\
\hline Supervisor Support & 2.66 & 0.99 & 2.62 & 0.95 & 1.44 & 1.53 & .00 & .24 \\
\hline Colleague Support & 2.91 & 0.74 & 2.80 & 0.74 & 9.88 & $18.44 * * *$ & .01 & .99 \\
\hline Strategic Alignment & 4.67 & 1.32 & 4.84 & 1.37 & 22.85 & $12.64 * * *$ & .00 & .95 \\
\hline Work Engagement & 3.81 & 1.47 & 3.90 & 1.39 & 6.13 & 2.98 & .00 & .41 \\
\hline Psychological Strain & 1.00 & 0.47 & 1.00 & 0.45 & 0.01 & 0.05 & .00 & .06 \\
\hline
\end{tabular}

Note. $* * * p<.001$ 
Table 2

Means, Standard Deviations, Zero-Order Correlations, and Internal Consistencies for all Research Variables $(N=1,601)$.

\begin{tabular}{|c|c|c|c|c|c|c|c|c|c|c|c|}
\hline & $M$ & $S D$ & 1 & 2 & 3 & 4 & 5 & 6 & 7 & 8 & 9 \\
\hline 1. Job Control (T1) & 3.60 & 0.98 & $(.92)$ & & & & & & & & \\
\hline 2. Supervisor Support (T1) & 2.62 & 0.95 & $.20 * * *$ & $(.92)$ & & & & & & & \\
\hline 3. Colleague Support (T1) & 2.80 & 0.74 & $.12 * * *$ & $.48 * * *$ & $(.86)$ & & & & & & \\
\hline 5. Job Demands (T1) & 3.78 & 0.78 & $.06^{*}$ & -.01 & -.01 & $.06^{*}$ & $(.86)$ & & & & \\
\hline 6. Work Engagement (T1) & 3.91 & 1.39 & $.36 * * *$ & $.41 * * *$ & $.36 * * *$ & $.41 * * *$ & .04 & $(.92)$ & & & \\
\hline 7. Psychological Strain (T1) & 1.00 & 0.45 & $-.24 * * *$ & $-.31 * * *$ & $-.26 * * *$ & $-.23 * * *$ & $.15 * * *$ & $-.46 * * *$ & $(.90)$ & & \\
\hline 8. Job Control (T2) & 3.61 & 0.97 & $.59 * * *$ & $.13 * * *$ & $.10 * * *$ & $.26 * * *$ & .02 & $.25 * * *$ & $-.23 * * *$ & $(.93)$ & \\
\hline 9. Supervisor Support (T2) & 2.62 & 0.94 & $.11 * * *$ & $.55 * * *$ & $.31 * * *$ & $.14 * * *$ & .00 & $.27 * * *$ & $-.25 * * *$ & $.24 * * *$ & $(.92)$ \\
\hline 10. Colleague Support (T2) & 2.75 & 0.76 & $.07 *$ & $.31 * * *$ & $.56 * * *$ & $.12 * * *$ & .00 & $.27 * * *$ & $-.19 * * *$ & $.15^{*}$ & $.46^{* * *}$ \\
\hline 11. Strategic Alignment (T2) & 4.88 & 1.39 & $.21 * * *$ & $.14 * * *$ & $.09 * * *$ & $.69 * * *$ & .05 & $.34 * * *$ & $-.18 * * *$ & $.31 * * *$ & $.20 * * *$ \\
\hline 12. Job Demands (T2) & 3.72 & 0.79 & .04 & -.01 & .02 & .01 & $.62 * * *$ & .02 & $.15 * * *$ & $.07 *$ & -.01 \\
\hline 13. Work Engagement (T2) & 3.92 & 1.41 & $.36 * * *$ & $.41 * * *$ & $.27 * * *$ & $.37 * * *$ & .03 & $.71 * * *$ & $-.36 * * *$ & $.35 * * *$ & $.41 * * *$ \\
\hline 14. Psychological Strain (T2) & 1.00 & 0.46 & $-.18 * * *$ & $-.31 * * *$ & $-.19 * * *$ & $-.19 * * *$ & $.09 * *$ & $-.28 * * *$ & $.56 * * *$ & $-.28 * * *$ & $-.33 * * *$ \\
\hline
\end{tabular}

\begin{tabular}{llllll}
\hline & 10 & 11 & 12 & 13 & 14 \\
\hline 10. Colleague Support (T2) & $(.87)$ & & & & \\
11. Strategic Alignment (T2) & $.14^{* * *}$ & $(.93)$ & & & \\
12. Job Demands (T2) & .05 & $.08^{*}$ & $(.86)$ & & \\
13. Work Engagement (T2) & $.36^{* * *}$ & $.45^{* * *}$ & $.07^{*}$ & $(.93)$ & \\
14. Psychological Strain (T2) & $.26^{* * *}$ & $-.22^{* * *}$ & $.14^{* *}$ & $-.46^{* * *}$ & $(.91)$ \\
\hline
\end{tabular}

Note. Cronbach's alpha coefficients are listed on the diagonal. T1 $=$ Time $1, \mathrm{~T} 2=$ Time $2 .{ }^{*} p<.05,{ }^{*} p<.01, * * * p<.001$. 
Table 3

Results of the Structural Equation Modelling Analyses $(N=1,601)$

\begin{tabular}{|c|c|c|c|c|c|c|c|c|c|c|c|c|c|}
\hline Structural Model Description & $\chi^{2}$ & $d f$ & $\chi^{2} / d f$ & $S R M R$ & $T L I$ & $C F I$ & PCFI & RMSEA & $A I C$ & $\begin{array}{c}\text { Model } \\
\text { Comparison } \\
\end{array}$ & $\Delta \chi^{2}$ & $\Delta d f$ & $p$ \\
\hline $\begin{array}{c}\text { M1: T1 variables onto T2 } \\
\text { counterparts }\end{array}$ & 6132.96 & 1322 & 4.64 & .07 & .92 & .93 & .86 & .05 & 6458.96 & - & - & - & - \\
\hline $\begin{array}{c}\mathrm{M} 2: \mathrm{M} 1+\mathrm{T} 1 \text { resources onto } \mathrm{T} 2 \\
\text { engagement, } \mathrm{T} 1 \text { demands onto } \mathrm{T} 2 \\
\text { strain }\end{array}$ & 6107.06 & 1317 & 4.64 & .07 & .92 & .93 & .86 & .05 & 6443.06 & $\mathrm{M} 1$ and $\mathrm{M} 2$ & 25.90 & 5 & $<.001$ \\
\hline $\begin{array}{c}\mathrm{M} 3: \mathrm{M} 2+\mathrm{T} 1 \text { demands onto } \mathrm{T} 2 \\
\text { engagement, } \mathrm{T} 1 \text { resources onto } \mathrm{T} 2 \\
\text { strain }\end{array}$ & 6092.96 & 1312 & 4.64 & .07 & .92 & .93 & .85 & .05 & 6438.96 & M2 and M3 & 14.10 & 5 & $<.05$ \\
\hline $\begin{array}{c}\mathrm{M} 4: \mathrm{M} 3+\mathrm{T} 1 \text { strain onto } \mathrm{T} 2 \\
\text { demands, } \mathrm{T} 1 \text { engagement onto } \mathrm{T} 2 \\
\text { resources }\end{array}$ & 6047.33 & 1307 & 4.63 & .06 & .92 & .93 & .85 & .05 & 6403.33 & M3 and M4 & 45.63 & 5 & $<.001$ \\
\hline \multirow[t]{2}{*}{$\begin{array}{c}\text { M5: All T1 variables onto all T2 } \\
\text { variables }\end{array}$} & 5987.49 & 1280 & 4.68 & .05 & .92 & .93 & .83 & .05 & 6397.49 & M4 and M5 & 59.84 & 27 & $<.001$ \\
\hline & & & & & & & & & & M1 and M5 & 145.47 & 42 & $<.001$ \\
\hline
\end{tabular}

Note. T1 = Time 1, T2 = Time 2; M1 = Model 1, M2 = Model 2, .. M5 = Model 5; TLI = Tucker-Lewis Index; CFI = comparative fit index; PCFI = parsimoniously adjusted value of the comparative fit index; SRMR standardized root mean-square residual; RMSEA = standardized root mean-square error of approximation; $\mathrm{AIC}=$ Akaike information criterion 


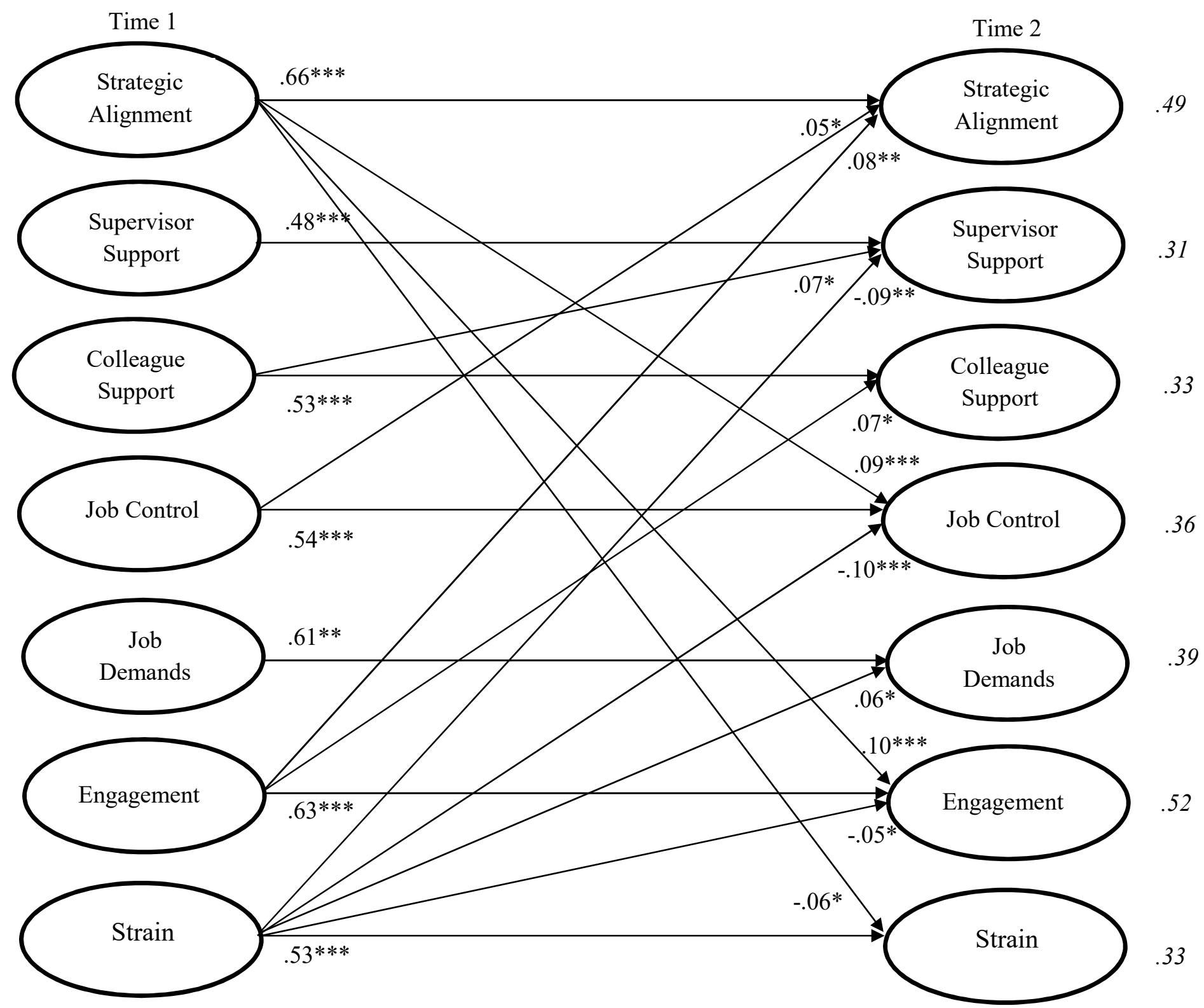

Figure 1. Cross-lagged structural model across two waves. Only the significant relationships are illustrated. Values represent standardized parameter estimates. Variances explained in the dependent variables at Time 2 are presented in italics. ${ }^{*} p<.05, * * p<.01,{ }^{* *} p<.001$. 
Table 4

Summary of Moderated Structural Equation Modelling $(N=1,601)$

\begin{tabular}{|c|c|c|c|c|c|c|c|c|c|c|c|}
\hline \multirow[b]{2}{*}{ Predictors (T1) } & \multicolumn{2}{|c|}{ Work Engagement (T2) } & \multicolumn{2}{|c|}{ Psychological Strain (T2) } & \multicolumn{6}{|c|}{ Model Fit } & \multirow[b]{2}{*}{ RMSEA } \\
\hline & $b(S E)$ & $\beta$ & $b(S E)$ & $\beta$ & $\chi^{2}$ & $d f$ & $\chi^{2} / d f$ & CFI & TLI & SRMR & \\
\hline Job Demands & $.01(.03)$ & .01 & $.01(.02)$ & .02 & & & & & & & \\
\hline Job Control & $.01(.03)$ & .01 & $-.02(.02)$ & -.03 & & & & & & & \\
\hline Job Demands x Job Control & $-.10(.06)$ & -.04 & $-.01(.03)$ & -.01 & & & & & & & \\
\hline$R^{2}$ & 52 & & 33 & & 6250.78 & 1440 & 4.34 & .93 & .92 & .05 & .05 \\
\hline Job Demands & $.01(.03)$ & .01 & $.01(.02)$ & .02 & & & & & & & \\
\hline Supervisor Support & $.03(.04)$ & .02 & $.00(.02)$ & -.01 & & & & & & & \\
\hline $\begin{array}{l}\text { Job Demands x Supervisor } \\
\text { Support }\end{array}$ & $-.06(.05)$ & -.03 & $-.02(.02)$ & -.02 & & & & & & & \\
\hline$R^{2}$ & $52^{\circ}$ & & 33 & & 6172.53 & 1440 & 4.29 & .93 & .92 & .05 & .05 \\
\hline Job Demands & $.01(.03)$ & .01 & $.01(.02)$ & .02 & & & & & & & \\
\hline Colleague Support & $.06(.06)$ & .02 & $-.04(.03)$ & -.04 & & & & & & & \\
\hline $\begin{array}{l}\text { Job Demands x Colleague } \\
\text { Support }\end{array}$ & $.01(.05)$ & .01 & $-.04(.03)$ & -.05 & & & & & & & \\
\hline$R^{2}$ & 52 & & 33 & & 6175.95 & 1440 & 4.29 & .93 & .92 & .05 & .05 \\
\hline Job Demands & $.01(.03)$ & .01 & $.01(.02)$ & .02 & & & & & & & \\
\hline Strategic Alignment & $.11(.02)$ & $.10 * * *$ & $-.03(.01)$ & $-.06^{*}$ & & & & & & & \\
\hline $\begin{array}{l}\text { Job Demands x Strategic } \\
\text { Alignment }\end{array}$ & $-.03(.04)$ & -.01 & $.03(.02)$ & .03 & & & & & & & \\
\hline$R^{2}$ & $52^{\circ}$ & & 33 & & 6268.15 & 1440 & 4.35 & .93 & .92 & .05 & .05 \\
\hline
\end{tabular}

Note. $\quad * p<.05, * * * p<.001 . \mathrm{T} 1=$ Time $1 ; \mathrm{T} 2=$ Time $2 . \mathrm{TLI}=$ Tucker-Lewis Index; CFI = comparative fit index; SRMR $=$ standardized root meansquare residual; RMSEA = standardized root mean-square error of approximation. 